\title{
EMBATES SEMIÓTICO-DISCURSIVOS EM REDES DIGITAIS BOLSONARISTAS: POPULISMO, NEGACIONISMO E DITADURA
}

\author{
SEMIOTIC-DISCURSIVE CONFRONTATION IN \\ BOLSONARIST DIGITAL NETWORKS: POPULISM, \\ NEGATIONISM AND DICTATORSHIP
}

\section{Danillo da Conceição Pereira Silva*}

\section{RESUMO}

Este artigo discute práticas discursivas relacionadas ao bolsonarismo online, enquanto manifestação de um populismo digital de extrema-direita. Para tanto, são focalizados embates semiótico-discursivos instaurados em trajetórias textuais mobilizadas para significar os processos históricos relativos à Ditadura Civil-Militar brasileira (1964-1985). As interações analisadas foram desencadeadas a partir de uma postagem na conta oficial do presidente Jair Bolsonaro no Twitter, em 27 de março de 2019, às vésperas dos 55 anos do Golpe de 1964. Partindo de uma perspectiva teórico-metodológica pautada no rastreamento textual em redes digitais e em concepções pragmáticas e semióticas dos processos de significação, oferecemos algumas interpretações contingentes acerca do problema investigado. São elas: a cooptação de significantes vazios próprios da racionalidade populista para a instauração de negacionismos históricos estratégicos; a insistente (re)atualização de sentidos indexicais autoritários, antidemocráticos e antidireitos humanos nas trajetórias textuais e espaçotemporais do discurso bolsonarista online; e a fricção semiótico-discursiva nas disputas por enquadres metapragmáticos entre agentes discursivos bolsonaristas e seus oponentes em espaços públicos virtuais.

Palavras-chave: populismo digital ${ }_{i}$ bolsonarismo; trajetórias textuais; indexicalidade; metapragmática.

\section{ABSTRACT}

This article aims to discuss discursive practices related to online Bolsonarism, as a manifestation of extreme right-wing digital populism. For this purpose, semiotic-discursive clashes focused on textual trajectories mobilized to signify the historical processes related to the Brazilian Civil-Military Dictatorship (1964-1985) are focused. The analyzed interactions were triggered from a post on the official account of President Jair Bolsonaro on Twitter, on March 27, 2019, on the eve of the fifty-five years of the 1964 Coup. Starting from a theoretical and methodological perspective based on textual tracking in digital networks and in pragmatic and semiotic conceptions of the processes of signification,

\footnotetext{
* Instituto Federal de Alagoas, IFAL, Santana do Ipanema, AL, Brasil. danillosh@gmail.com Orcid: https://orcid.org/0000-0003-4704-1873
} 
we propose some contingent interpretations about the problems investigated here. They are: the co-optation of significant gaps typical of populist rationality for the establishment of strategic historical negations; the insistent (re) updating of authoritarian, anti-democratic and anti-human rights indexical meanings in the textual trajectories of the online bolsonarist (bolsonarista) discourse; the semiotic-discursive friction in disputes over metapragmatic frameworks between bolsonarist (bolsonarista) discursive agents and their opponents on virtual public spaces.

Keywords: digital populism; bolsonarism; textual trajectories; indexicality; metapragmatics.

\section{INTRODUÇÃO}

Este trabalho é a materialização de um engajamento intelectual e político movido pela busca pulsional por produzir inteligibilidades críticas e indisciplinares, desde os estudos aplicados da linguagem, acerca da realidade sociopolítica brasileira, especialmente após as eleições de 2018. Assim, usando lentes teórico-analíticas que me são mais e menos familiares, arrisco-me na tarefa de oferecer interpretação para uma pequena, mas relevante, parte das multidimensionais e imbricadas questões que se impõem ao nosso campo do saber: a ascensão de populismos (LACLAU, 2005, 2014) de extrema-direita; a digitalização do político; e as consequências da imbricação desses fenômenos para a análise da comunicação política, suas dinâmicas semiótico-discursivas e seus modos de agência na esfera pública pósdigital. Busco enfatizar, dentre outras coisas, o que tem acontecido às nossas subjetividades e sociabilidades, a partir da consideração dos regimes de significação que performativamente as produzem, cada vez mais velozes, dinâmicos, fluidos e infecciosos.

Assim, reconhecendo que "as redes virtuais de comunicação têm servido como canais mais ou menos legitimados e influentes para posicionamentos sobre o regime militar brasileiro" e que "eles têm sido particularmente importantes no revisionismo da extrema direita em sua luta contra a memória crítica, hegemônica e legitimada socialmente sobre o regime militar" (NAPOLITANO, 2015, p. 16), meu objetivo neste trabalho é investigar algumas práticas discursivas relacionadas ao bolsonarismo online, enquanto manifestação de um populismo digital (CESARINO, 2019) de extrema-direita. De modo mais específico, focalizarei os embates semiótico-discursivos produzidos no trânsito de textos acionados para significar os processos históricos relativos à Ditadura Civil-Militar brasileira (1964-1985). As interações analisadas foram disparadas em função de uma postagem na conta oficial do presidente Jair Bolsonaro no Twitter, @jairbolsonaro, em 27 de março de 2019. 
Este estudo está organizado em quatro seções. Na primeira delas, busquei delinear os contornos do fenômeno político bolsonarista, articulando sua emergência à história colonial brasileira e à atual digitalização da comunicação política, nos termos de um populismo digital de extrema-direita. Em seguida, aprofundando a discussão sobre significantes flutuantes na contenda política populista, apresento o negacionismo histórico como uma estratégia do bolsonarismo para a deslegitimação da memória social hegemônica da Ditadura Civil-Militar brasileira. Na terceira seção, recorrendo a perspectivas sobre a mobilidade do discurso e à dimensão metapragmática da linguagem, exploro as especificidades da comunicação política em sociedades pós-digitais. Por fim, narro os procedimentos de rastreamento textual, e do exercício de seguir links em redes digitais, os quais me levaram à geração dos dados analisados, a partir de interações no Twitter. Em linhas gerais, produzo interpretações acerca dos embates semiótico-discursivos travados nessas interações, em face de disputas por enquadres metapragmáticos e da projeção de equivalências tempo-espaciais, as quais apontam para a fricção nos processos indexicalização de sentidos autoritários, antidemocráticos e antidireitos humanos nas práticas discursivas do bolsonarismo online.

\section{O BOLSONARISMO ONLINE E A RETÓRICA DE UM POPULISMO DIGITAL}

Diante dos esforços contínuos de diferentes setores da sociedade na busca por produzir inteligibilidade sobre o momento político em que o Brasil mergulhou, especificamente desde o golpe de Estado sofrido pela presidenta Dilma Rousseff (Partido dos Trabalhadores - PT), em 2016, culminando com a eleição do então deputado federal, Jair Bolsonaro (Partido Social Liberal - PL), em 2018, basicamente dois caminhos interpretativos têm sido assumidos por analistas de diferentes orientações. O primeiro deles, talvez o mais impulsivo em face do terror antidemocrático, mobilizado por visões mais liberais, caracteriza o presente momento como uma irrupção da História, um momento abrupto de descontinuidade e surpresa numa trajetória de coisas que teriam significado, até pouco tempo, a chegada da extrema-direita à Presidência da República como improvável, incerta e até risível.

Uma segunda perspectiva, validada por análises críticas do status atual do capitalismo (na sua relação de contiguidade com o colonialismo) e de sua intrusão 
sistemática na vida formalmente democrática das instituições brasileiras ${ }^{1}$, aponta para as relações de filiação material e simbólica do momento presente com dinâmicas históricas sistematicamente (mas não linearmente) instauradas, onipresentes e constitutivas no/do tecido social e político do Brasil, inclusive como resposta a uma guinada mundial em direções particularmente autoritárias de espectros políticos das direitas. Assim, segundo argumenta a antropóloga Lilia Schwarcz (2019, p. 224) acerca do autoritarismo brasileiro, "o nosso passado escravocrata, o espectro do colonialismo, as estruturas de mandonismo e patriarcalismo, a da corrupção renitente, a discriminação racial, as manifestações de intolerância de gênero, sexo e religião, todos esses elementos juntos tendem a reaparecer", como um fenômeno sistêmico que comparece insistentemente na cena política do país, sob versões multifacetadas e de incisividade progressiva.

Alinhando-me a essa segunda via interpretativa, arrisco-me a dizer que o bolsonarismo pode ser caracterizado como um tipo particular de composição de forças políticas, econômicas, religiosas e midiáticas que, apesar de catalisar uma miríade de conteúdos difusos em suas mensagens, e de neste momento político nacional específico ganhar ampla repercussão e notoriedade devido à sua chegada aos altos escalões do poder institucional, move-se em direções vetoriais bastante conhecidas das democracias liberais ao redor do mundo. Isto, de modo especial, naquelas cujas máquinas estatais que viabilizam o dito funcionamento democrático se constituem como resultado da progressão histórica de administrações coloniais (QUIJANO, 2005). Ou seja, pautadas em lógicas de desumanização, hierarquização e extermínio, próprias do racismo.

Nessas sociedades, fundadas sob a égide do colonialismo, processo histórico de duração específica, permanece em vigência a colonialidade como expressão de uma "matriz de poder colonial" (QUIJANO, 2005), a qual as organiza segundo princípios de "exploração e de dominação em múltiplas dimensões da vida social, desde a económica [sic.], sexual ou das relações de género [sic.], até às organizações políticas, estruturas de conhecimento, instituições estatais e agregados familiares" (GROSFOGUEL, 2008, p. 126). Em função desse modo de estruturação das

1. O que aqui estou chamando de "vida formalmente democrática das instituições brasileiras" alude à compreensão produzida por conjunto de leituras sociológicas e políticas, praticada historicamente pelos movimentos sociais e por alguns setores intelectuais. Tais perspectivas ressaltam o fato de que o funcionamento aparente de instituições fundamentais de um regime jurídico-político democrático não garante a efetividade universal desse status e, por vezes, escamoteia a produção de sujeitos ininteligíveis e de zonas extensas de violências e violações de direitos humanos. $\mathrm{Na}$ esteira dessas visadas críticas sobre o Estado estão diferentes propostas, a exemplo das noções de democracia radical e vidas matáveis, na obra de Judith Butler, e de vida nua e estado de exceção, de Giorgio Agamben. 
relações de poder, diferentes níveis da vida social e política passam a replicar/ atualizar "múltiplas e heterogéneas [sic.] hierarquias globais de formas de dominação e exploração" nas quais "a hierarquia étnico-racial do fosso cavado entre o europeu e o não-europeu reconfigura transversalmente todas as restantes estruturas globais de poder" (GROSFOGUEL, 2008, p. 123).

Em outras palavras, se a conjunção e a projeção das forças e dos modos de organização do político próprias do bolsonarismo podem ser tomadas sob o signo da novidade, especialmente no que diz respeito aos seus modos de operação e intervenção na esfera pública, o mesmo não pode ser dito das matrizes ideológicas primárias e das lógicas de subordinação social e econômica, históricas, que gestaram o que agora se toma como fenômeno novo, por isso candente de interpretações que deem conta dessas intricadas articulações e seus regimes semióticos.

A exemplo disso, um olhar desde dentro das periferias geopolíticas e econômicas dos centros urbanos e das zonas rurais de nosso país denuncia ter sido historicamente gestado e implantado o projeto-piloto de um Brasil sob uma política de cunho fascista, neoliberal, armamentista, militarista, enfim, a qual agora chamamos bolsonarista, justamente por ter encontrado na figura de Jair Bolsonaro, e nas forças e tecnologias múltiplas ${ }^{2}$ que ele conseguiu congregar em torno de si (CESARINO, 2020; NEMER, 2019), o ator que a alçou à superfície institucional do poder. Tal fato se deve, dentre outros elementos contextuais igualmente complexos, ao auge de uma crise de representatividade política produzida, em grande parte, pela vontade econômica incrustrada na esfera política; à falência das linguagens e da capacidade de imaginação política das esquerdas democráticas nacionais (e do campo progressista, em geral) e da capacidade de comunicação com sua tradicional base eleitoral, a classe trabalhadora; e, certamente, à chegada do açoite a grupos até então protegidos em função de seus privilégios estruturais de classe e de raça, por exemplo. O bolsonarismo é, assim, um tipo grotesco de metonímia política, é a parte de um todo denso, complexo e constitutivamente incrustrado no organismo da política institucional brasileira.

2. Momentos antes do primeiro turno das eleições presidenciais brasileiras de 2018, 60\% dos eleitores de Jair Bolsonaro entraram em contato com informações repassadas via WhatsApp (LEMOS et al, 2018). Além disso, $98,21 \%$ dos eleitores do mesmo candidato receberam mensagens com conteúdo falso durante o processo eleitoral, sendo que, desses, $89,77 \%$ não desconfiaram de sua veracidade, conforme pesquisa do BigData/Avaanz (PASQUINI, 2018). Desse modo, pode-se afirmar que a campanha eleitoral do atual presidente brasileiro se caracteriza por um uso extensivo e de alta eficácia, sem precedentes, do recurso às mídias digitais. Se na campanha eleitoral os esforços eram centrados no uso massivo do WhatsApp, durante seu mandato o Twitter tem sido o grande vetor de suas estratégias comunicacionais populistas. 
Do ponto de vista da racionalidade política em funcionamento no bolsonarismo, seguindo a chave de leitura oferecida pela obra de Ernesto Laclau $(2005,2014)$, não seria forçoso afirmar que esse se trata de um tipo de populismo de extrema direita, com uma linguagem sensivelmente afetada pelas dinâmicas comunicativas das mídias digitais 3.0, o que levou Cesarino (2019) a tratá-lo como um tipo de populismo digital. Isto é, para além da regularidade de características tradicionais do populismo como modo de operação do político, o populismo digital não corresponde simplesmente a um incremento das tecnologias digitais, e da web, à mecânica populista, mas à instauração de padrões discursivos específicos resultantes de efeitos difusos da digitalização do político. Assim, pode-se argumentar, conforme Cesarino (2019, p. 530), dentre outras coisas, acerca da irrupção de um funcionamento pautado na "mobilização permanente através de conteúdos alarmistas e conspiratórios", na técnica do "espelho invertido do inimigo e devolução de acusações" e, especialmente, na "criação de um canal direto e exclusivo de comunicação entre a liderança e seu público através da deslegitimação de instâncias de produção de conhecimento autorizado na esfera pública (notadamente, a academia e a imprensa profissional)". Tais aspectos impactam diretamente o sentimento de representação política, bem como a intensidade e a ostensividade do engajamento dos atores sociais digitais articuladores do bolsonarismo.

É justamente pautado nessa última característica, atinente à deslegitimação de instâncias tradicionalmente mediadoras das interpretações hegemônicas sobre os fatos, especialmente via redes sociais, que o investimento negacionista do bolsonarismo online sobre os eventos da Ditadura Civil-Militar vai incidir. Isso, como discutirei na seção seguinte, enquanto parte de uma mobilização ideológica específica que busca disputar sentidos inscritos na memória social brasileira em torno de uma cultura de direitos humanos minimamente estabelecida. Tal dinâmica se deu, vale dizer, recorrendo a acordos escusos, de cunho liberal, entre setores antes mobilizados em favor da ditadura, a exemplo da mídia empresarial, conforme sustenta Napolitano (2019).

\section{SIGNIFICANTES FLUTUANTES E O NEGACIONISMO HISTÓRICO DA DITADURA CIVIL-MILITAR BRASILEIRA}

Uma das características da racionalidade política populista que se mostra abundante nas práticas discursivas bolsonaristas diz respeito à cooptação daquilo que Laclau (2005) nomeou como significantes flutuantes. Trata-se de palavras e imagens que, embora sejam centrais para instauração da hegemonia de um projeto político 
(e sua vitória num pleito eleitoral, por exemplo), não possuem um conteúdo estável, claro, transparente e sempre invocável sem a necessidade de procedimentos de estabilização e/ou delimitação da natureza e do escopo de sua significação, por isso em constante disputa no jogo político.

Nesse sentido, um exemplo bastante notório da política recente brasileira é a disputa em torno do significante golpe, travada especificamente no contexto dos eventos que conduziram à deposição da ex-presidenta Dilma Rousseff, o que foi amplamente registrado nas práticas discursivas da mídia nacional. Enquanto grupos alinhados às esquerdas e a posições progressistas reivindicavam a ilegalidade de tal processo, enquadrando-o como um golpe jurídico-político-midiático, orquestrado por forças conversadoras, grupos ligados majoritariamente às direitas predicavam tal processo como impeachment ou impedimento, buscando, assim, afastar o sentido de golpe, por considerar o referido processo político legal e democrático. Tal foi a disputa em torno desse significante, que as redes sociais chegaram a mobilizar um campanha midiática impulsionada pela basbtag \#foigolpe. ${ }^{3}$

$\mathrm{Na}$ teoria do populismo, o jogo político não é tomado como atrelado à esfera da conciliação de racionalidades individuais, deliberantes segundo argumentações lógicas, cingidas de plausibilidades universais, como preconizam perspectivas clássicas do político, mas, ao contrário, está submetido à disputa e ao dissenso permanentes e incontornáveis. Esses, por sua vez, mobilizados mediante a convocação de afecções instauradas por regimes de imagens, valores e simbolismos que operam em função da produção de quadros hegemônicos, temporários e contingentes, de sobreposição de forças.

Nesse sentido, significantes cujos significados estão em suspenso, como legalidade, corrupção, justiça, embora sejam demandados constantemente no processo democrático, "sofrem a pressão estrutural de projetos hegemônicos rivais", uma vez que "seu significado é indeterminado entre fronteiras alternativas de equivalência" (LACLAU, 2005, p. 197). É seguindo esse padrão que significantes como ditadura militar e direitos bumanos, colocados no centro das práticas discursivas focalizadas neste artigo, ainda que sejam historicamente significados segundo as interpretações que lhes foram conferidas pelas "cadeias de equivalências" (LACLAU, 2005, p. 197) dos campos democráticos engajados na luta por justiça social, identificados como as esquerdas e os setores progressistas, possam ser, então, convocados nas práticas discursivas situadas, sob conteúdos antagônicos a esses, por setores

3. Para uma compreensão mais detida e multifocal sobre as práticas discursivas que significaram o Golpe de 2016, ver Foi Golpe! O Brasil de 2016 em análise (GALVÃO; ZAIDAN, SALGUEIRO, 2019). 
de cariz autoritário e antidemocrático, como a extrema-direita e o bolsonarismo, propriamente.

Voltando a focalizar a questão das batalhas de significação na esfera do político, parece-me produtivo pensar no modo como a flutuação de significantes é instada pela vontade negacionista bistórica como um tipo de revisionismo ideológico (NAPOLITANO, 2019). Esse tipo de operação sobre a realidade busca apagar/negar a existência de fatos específicos ou alterar drasticamente a interpretação consagrada a eles pela historiografia (contramemórias), ainda que sem nenhum tipo de evidência factual nova. Em geral, o que desencadeia movimentações dessa natureza, intenta, única e exclusivamente, a validação de um arcabouço ideológico próprio e de um projeto de poder que, para se impor, precisa alterar eventos que podem colocar em xeque um grupo de consensos e acordos que garantem seu efeito de legitimidade. Um exemplo desse tipo de expediente nefasto, corrente na comunicação política da extrema-direita online, é a produção de narrativas que visam a negar o modelo de escravização comercial produzida pelos europeus durante o período de colonização das Américas, o qual foi responsável pelo tráfico, exploração e extermínio de diferentes povos do continente africano, entre os séculos XVI e XVII ${ }^{4}$.

Desse modo, outro caso de projeção de uma narrativa "que não se baseia obrigatoriamente em fatos, uma vez que seleciona, em primeiro lugar, uma mensagem final e só depois arruma um bom argumento para justificá-la" (SCHWARCZ, 2019, p. 20) é o que ocorre com os graves eventos que marcaram a política nacional entre 1964 e 1985. Nesse sentido, tem sido um esforço contínuo do discurso bolsonarista questionar a memória social hegemônica, e aquela produzida no debate acadêmico, a qual toma os eventos deste referido período histórico como antidemocráticos, autoritários, violência de Estado, tortura sistemática, perseguição política, calcados, então, em graves violações de direitos bumanos (BRASIL, 2014). Por essa razão, dignos de serem classificados, do ponto de vista da teoria política, como golpe e como ditadura (NAPOLITANO, 2015), e não como revolução ou contrarrevolução, como insistem em predicá-los os bolsonaristas.

Nesse contexto, o discurso negacionista do bolsonarismo online vai procurar disputar tais significantes em flutuação, mediante procedimentos vários, dentre

4. Discursos dessa natureza, calcados em racismos e autoritarismos, em geral, buscam atribuir aos povos escravizados a responsabilidade pelo modelo escravagista, recorrendo a falácias como a de que, em África, já havia esse tipo de regime de exploração; ou ao argumento de uma suposta convivência dos próprios povos africanos em seu processo de escravização e extermínio. Nesses termos, Jair Bolsonaro, quando candidato à presidência, em entrevista à TV Cultura, chegou a afirmar: "Se você for ver a história realmente, o português não pisava na África, era [sic.] os próprios negros que entregavam os escravos" (BOLSONARO, 2018). 
eles aqueles apontados por Cesarino (2019), e já referidos na seção anterior, como característicos do populismo digital bolsonarista. Quais sejam: a mobilização de conteúdos alarmistas e conspiratórios; a devolução irrefletida e estratégica de acusações; e a deslegitimação de instâncias de produção do conhecimento em favor da comunicação direta com o líder carismático - então aplicados à disputa de narrativa ou aos embates semiótico-discursivos, pautados no negacionismo histórico, em torno da Ditadura Civil-Militar brasileira.

\section{MOBILIDADE TEXTUAL, METAPRAGMÁTICAS E DISCURSO POLÍTICO ONLINE}

Seja pela natureza móvel e pelo caráter dinâmico que as disputas políticas imprimem nos regimes de significação, seja pela aceleração dos fluxos semióticoidentitários ocasionados pela digitalização da vida na web, parece-me inegável que somente um modelo de interpretação da significação que levasse em conta as trajetórias de textos e sentidos seria capaz de informar satisfatoriamente análises da dimensão discursiva de processos políticos online. Esse fato ganha particular relevância no contexto de sociedades pós-digitais (BLOMMAERT, 2019), dentre outras coisas, marcadas pelo impacto de inovações de alta tecnologia, pela hibridização de sistemas midiáticos, bem como pela discretização dos limites entre o onlineoffline. Tais processos, que afetam em cheio a intensidade do caráter mediado da comunicação política, são, em geral, produzidos pelas tendências de universalização de redes sem-fio e de dispositivos móveis, de modo que o digital deixa de ser simplesmente um processo em emergência, uma vez que "as infraestruturas digitais tornaram-se parte do que é convencionalmente descrito como "estrutura social" (BLOMMAERT, 2019, p. 1).

Esse fato põe em evidência a limitação dos princípios ontológicos e epistemológicos tradicionalmente praticados nos estudos linguísticos, pautados, de modo geral, no essencialismo, a crença de que os significados são propriedades imanentes aos signos ou aos sistemas linguísticos enquanto realidades autônomas, afastando-se do caráter inelutavelmente social da linguagem. No logocentrismo, que focaliza como ente privilegiado da produção de significados os signos linguísticos, em sentido estrito, desconsiderando a hipersemiotização da vida social e das práticas comunicativas. No representacionalismo, o qual toma a relação entre linguagem e realidade como especular, ignorando a centralidade dos processos de mediação semiótica e da dimensão performativa da linguagem. Na estaticidade, como perspectiva de estudo sobre a significação centrada na estabilidade e na fixidez espaço-temporal, não contemplando a dimensão (trans)local e (trans)temporal das 
práticas (trans)textuais. E no monocentrismo, como modelo que privilegia a relação de contiguidade entre polos estanques de comunicação (sistema falante/ouvinte), invisibilizando o caráter multicêntrico das dinâmicas de produção e de circulação de signos, prementes nas sociedades atuais ${ }^{5}$.

Tais ideologias linguísticas sobre comunicação humana, em geral, e sobre comunicação política, em específico, estão postas sob intensa revisão em campos como a Linguística Aplicada indisciplinar ou crítica. Pesquisas engajadas nessa área têm produzido modelos epistemológicos alternativos que permitam às nossas teorizações e análises fazerem sentido diante das características do mundo atual. Assim, parece inevitável reconhecer a necessidade de abandonar "teorias linguísticas que se projetam como transparentes e condutoras da palavra definitiva sobre a linguagem" (MOITA LOPES, FABRÍCIO, 2019, p. 713). É nesse âmbito que conceitos como o de mobilidade do discurso têm sido acionados para compreender o modo como os processos de comunicação, enquanto instâncias de projeção semiótico-identitária, se desenrolam na atualidade.

Nesse escopo, a noção de entextualização corresponde ao recurso teóricoanalítico que busca dar conta de como "os discursos são descontextualizados sucessivamente ou simultaneamente e metadiscursivamente recontextualizados, para que se tornem um novo discurso associado a um novo contexto e acompanhado por um metadiscurso" (BLOMMAERT, 2019, p. 7). Nesse processo contínuo de descontextualização/recontextualização a que os discursos estão submetidos, cada nova reentextualização fornece, de partida, um tipo de interpretação preferencial para esse discurso. Ou seja, há que se atentar para a potência semiótica dos processos implicados na mobilidade textual, os quais sempre afetam os modos de significação dos textos que circulam, ou que viajam, em múltiplas e incessantes trajetórias, instaurando sempre novos processos de contextualização nas práticas sociais e intersubjetivas em que são arregimentados (SILVA, Daniel, 2019; FABRÍCIO, 2014).

Conforme Varis e Blommaert (2015), em processos como a distribuição massiva de mensagens e sua replicação em dinâmicas específicas da comunicação online, como em ações de compartilhamento (retweets, por exemplo), o que se dá não é um processo de repetição mimética, ou seja, do 'mesmo' conteúdo, da mesma mensagem. Em vez disso, o que ocorre é uma série de reentextualizaçãoes que

5. Para uma visão mais aprofundada das desestabilizações epistemológicas produzidas pelas demandas sociopolíticas e comunicacionais do mundo atual nas perspectivas de linguagem, praticadas por perspectivas pragmáticas e semióticas da Linguística Aplicada, ver Szundy e Fabrício (2019) e Moita Lopes e Fabrício (2019). 
afetam/alteram os processos de significação mediante seu trânsito. Dito de outro modo, as dinâmicas de mobilidade de discursos, inclusive daqueles produzidos em práticas políticas online, intensificadas e aceleradas pelas possibilidades de interconexão em rede, impactam também as possibilidades de circulação do discurso e, consequentemente, os modos de produção de significados políticos. Repelindo, então, uma visão instrumentalista, as transformações ocasionadas pelas tecnologias digitais da comunicação influenciam a estrutura do que entendemos como interação e como relações subjetivas, temporais e espaciais dela derivadas.

Outro fator importante para a compreensão da produção de significados como uma atividade móvel, policêntrica e multidimensional nas práticas discursivas online diz respeito ao caráter indexical (BLOMMAERT, 2019; PINTO, 2019; SILVERSTEIN, 1993) da linguagem. Esse faz alusão a natureza imbricada e constitutiva do funcionamento de diferentes níveis dos processos de significação, desfazendo binarismos tradicionais que regulam o modo de compreender o problema do significado nos estudos da linguagem, a exemplo das referências à dimensão local e à dimensão global da questão contextual. Ou seja, enquanto perspectivas imobilistas e unidimensionais invocam a categoria contexto para produzir explanações analíticas sobre discursos que hora privilegiam isoladamente sua dimensão emergente (instável), e hora o fazem em relação à sua dimensão mais estruturada (estável), numa perspectiva indexical da significação esses dois planos são encarados como camadas sobrepostas e articuladas.

Assim, "os signos, a um só tempo, pressupõem e criam seus contextos" (SILVA, 2014, p. 73), destacando a relação intrínseca entre dimensão pragmática da significação - o emprego localizado de recursos semióticos em práticas de linguagem específicas - e sua dimensão metapragmática - aquela relativa ao modo como os elementos indexicais, pragmáticos, são articulados aos significados socioculturais, históricos e políticos. Em outras palavras, a circulação de textos e signos em diferentes trajetórias é "um fenômeno metapragmático, que arregimenta a pragmática desses mesmos signos" (SILVA, 2014, p. 73).

Segundo uma perspectiva indexical das práticas de significação online, nas quais tanto a ação humana quanto aquela não-humana são potencialmente indexicais ${ }^{6}$, os

6. Nesse sentido, abordagens pós-humanistas têm enfatizado a agência de entes não-humanos, a exemplo de redes, interfaces, dispositivos móveis, aparatos técnicos e materiais de toda sorte, conjuntamente com os modos de agência de entes humanos, na produção de relações simétricas e emergentes de associação. Perspectivas como essas alteram a constituição do que tem sido nomeado como "o social" na tradição do pensamento sociológico ocidental (LATOUR, 2012). Nesse sentido, parece importante considerar a possibilidade de produção de significados sociais indexicais na relação entre agências humanas e não-humanas, especialmente no âmbito da comunicação política online. 
recursos semiótico-discursivos empregados apontam para sentidos socioculturais mais amplos, os quais são indissociáveis dos regimes semânticos e políticos de inteligibilidade dos discursos (e dos sujeitos), recuperáveis entre contextos e interações (SILVA, Danillo, 2019). Desse modo, é mediante dinâmicas constantes de repetição/ alteração de regimes semióticos reconhecíveis, mais densamente sedimentados na cultura, que tais "características semióticas carregadas ideologicamente da linguagem (indexicalizadas) aparecem como uma camada de significado histórico translocal, mas encenada localmente" (BLOMMAERT, 2015, p. 107).

Nesse sentido, em face da potencial relativização do suposto caráter estanque das relações entre tempo e espaço, as quais são pano de fundo dessa imbricação agonística entre dimensão local e translocal das práticas semiótico-discursivas, se oferece um recurso interpretativo amplo para dimensionar os embates em torno do discurso bolsonarista online, bem como da sua disputa de significantes vazios atrelados à memória social da Ditadura Civil-Militar brasileira. A meu ver, recorrer a essa lente interpretativa contribui para salientar o caráter fluido e móvel do que estou chamando de regimes de durabalibidade semiótica de um tempo histórico específico e dos significados a ele atribuídos na contenda política.

Por esse ângulo, boa parte do trabalho semiótico que constitui os embates discursivos dessas interações políticas online dizem respeito às disputas entre diferentes - e até mesmo antagônicos - enquadres metapragmáticos (PINTO, 2019) nas interações analisadas, as quais evocam diferentes regimes de entextualização e suas dinâmicas indexicais. Ou seja, o que está em disputa é "a orientação das falas com as quais interagem, usando tanto formas linguísticas conhecidas quanto outros recursos localmente relevantes, de tal maneira a 'restringir' ou 'ampliar' sua 'visão' do significado em construção" (PINTO, 2019, p. 226).

Sobre esse ponto, procurarei, na seção seguinte, pensar o papel da linguagem, em sentido amplo, e dos processos de significação, em sentido específico, na elaboração linguístico-semiótica do discurso bolsonarista online sobre o evento histórico analisado.

\section{EMBATES SEMIÓTICO-DISCURSIVOS EM TRAJETÓRIAS TEXTUAIS DO BOLSONARISMO ONLINE}

Nesta seção, buscarei construir uma interpretação contingente acerca de embates semiótico-discursivos instaurados nas trajetórias textuais projetadas em redes digitais do bolsonarismo online. Para isso, rastrearei os efeitos de sentido indexicalmente produzidos pelo movimento de textos desencadeados a partir de 
uma postagem realizada pelo presidente Jair Bolsonaro, em sua conta oficial no Twitter (@jairbolsonaro),em 27 de março de 2019, às vésperas dos 55 anos do Golpe Civil-Militar de 1964. Esse tipo de expediente metodológico e analítico, pautado no rastreamento textual (FABRÍCIO, 2014; BOAVENTURA, 2018), busca perspectivar a mobilidade e a fricção de signos e significados por entre diferentes espaçostempos. Desse modo, seguir textos implica focalizar dimensões multifacetadas "que envolvem diálogos entre elementos semânticos de diferentes dimensões sócio-históricas e que constituem formas desterritorializadas e multisituadas de compreensão/construção das experiências sociais" (BOAVRNTURA, 2018, p. 19).

A busca que me levou aos enunciados a partir dos quais os dados desta pesquisa foram gerados se inicia com o aparecimento, no feed do meu perfil pessoal no Facebook ${ }^{7}$, de uma postagem feita por um dos meus amigos na rede. Essa postagem replicava o link de uma matéria jornalística publicada em 10 de abril de 2019, na seção Política do site Huffpost Brasil ${ }^{8}$, intitulada 45 tuítes que resumem os 100 primeiros dias de Bolsonaro no poder. A matéria recontextualizava postagens realizadas pelo presidente Jair Bolsonaro, membros de seu governo e seus filhos em contas no Twitter, segundo ordem cronológica, relativas aos cem primeiros dias de seu mandato. Vale ressaltar que isso não ocorria à totalidade dos posts disparados pelos referidos agentes bolsonaristas nesse período, mas apenas àqueles tomados pelo enquadre metapragmático projetado pelo site como polêmicos ou problemáticos.

Seguindo os links, ou seja, viajando entre a postagem no meu feed no Facebook, até o site de notícias e, de lá, passando à conta oficial de Bolsonaro no Twitter, busquei rastrear o deslocamento de textos, movimentos semioticamente significativos entre diferentes plataformas digitais, dimensões espaço-temporais e enquadres que sucessivamente modelavam seus modos de significar. Nesse movimento, cheguei até os atos de fala que, mais uma vez recontextualizados, aparecem neste artigo acadêmico mediante aplicação do recurso de captura de tela, a fim de serem analisados.

7. Cabe ressaltar a importância de padrões algorítmicos segundo as quais tais postagens chegaram até mim, quando do meu acesso ao Facebook nessa ocasião. Apesar de ter, no momento do rastreamento, mais de 2.500 amigos nessa rede social, o elemento que decide quais posts emergem primeiro (e mais regularmente nos meus acessos), nesse universo de constantes atualizações, tem relação tanto com dinâmicas de engajamento mútuo de usuários em atividades como "curtir", "comentar" e "compartilhar", quanto com padrões automatizados de programação próprios dessa rede social digital.

8. Disponível em: <https:/www.huffpostbrasil.com/entry/governo-bolsonaro-twitter_br_5cace52de 4b0e833aa31f36d>. Acesso em: 20 jan. 2020. 
Jair M. Bolsonaro

@jairbolsonaro

"Participamos da Revolução de 1964, identificados com os anseios nacionais de preservação das instituições democráticas, ameaçadas pela radicalização ideológica, greves, desordem social e corrupção generalizada." Roberto Marinho, Presidente da Globo, ao final do Regime Militar.

Translate Tweet

5:40 PM - Mar 27, 2019 - Twitter for iPhone

7.1K Retweets

40.5K Likes

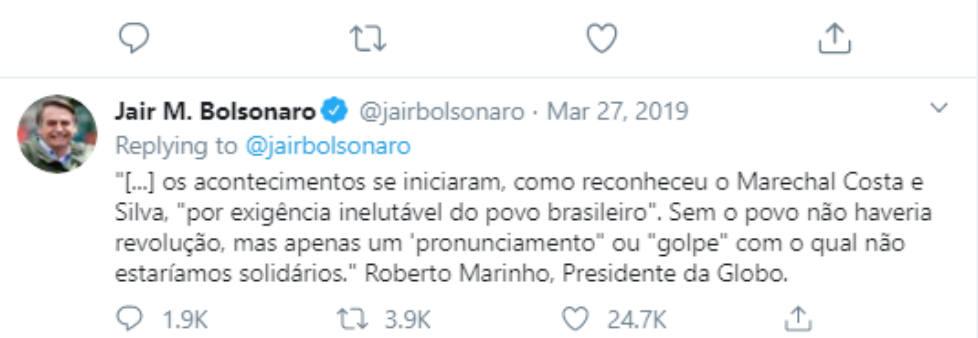

Figura 1: Tweets de Jair Bolsonaro em apologia à Ditadura Civil-Militar brasileira.

Fonte: <https://twitter.com/jairbolsonaro/status/1111005083196706817>. Acesso em: 19 fev. 2020.

Nos dois tweets representados na Figura $1{ }^{9}$, Bolsonaro entextualiza em seu discurso dois trechos extraídos do texto de um editorial do jornal $\mathrm{O} G l o b 0^{10}$, assinado pelo então presidente das Organizações Globo, Roberto Marinho, e publicado em 7 de outubro de 1984, sob o título Julgamento da Revoluçãa ${ }^{11}$. O referido editorial, lançado pouco antes do fim da ditadura, em 1985, e da chamada reabertura democrática, fazia, em nome do jornal, um elogio face ao balanço dos supostos ganhos trazidos para o povo brasileiro pelo golpe militar, predicado, então, como Revolução de 1964.

Certamente, as informações que essa trajetória semiótica e espaço-temporal faz precipitar acerca do que está sendo feito nessa interação específica podem

9. Disponível em: <https://www.huffpostbrasil.com/entry/governo-bolsonaro-twitter_br_5cace52de 4b0e833aa31f36d>. Acesso em: 20 jan. 2020.

10. Afora outras falas de Bolsonaro que fazem apologia direta à Ditadura Civil-Militar, as quais circulam de forma abundante nas plataformas digitais.

11. Apenas em 31 de agosto de 2013, o jornal O Globo reconheceu formalmente que o apoio ao Golpe Civil-Militar de 1964 foi um erro, com a publicação do editorial Apoio editorial ao golpe de 1964 foi um erro. 
ser inferidas a partir do nexo constitutivo entre a dimensão pragmática e a dimensão metapragmática em curso na arregimentação e na consequente significação das formas indexicais mobilizadas. Ou seja, nessa interação, vemos acionado um enquadre metapragmático que transforma as categorias linguísticas predicativas empregadas tais como preservação das instituições democráticas, radicalização ideológica, greves, desordem social, corrupção generalizada - em elementos indexicais que predicam valores específicos. Temos, assim, "uma metapragmática reflexivamente calibrada, ou seja, uma tentativa de controle de interpretação de uma fala determinada em sua realização ou sua resposta" (PINTO, 2019, p. 226b).

As relações translocais instauradas por esses atos de fala expressam a "indissolubilidade de espaço e de tempo" (BAKHTIN, 2014, p. 211), ou seja, o caráter cronotrópico dos signos. Os cronotopos "invocam e permitem [...] mundos sociais e políticos nos quais as ações se tornam dialogicamente significativas", de modo que "outras historicidade se reúnem na historicidade aqui e agora da produção e do entendimento" (BLOMMAERT, 2015, p. 109-110). Tendo isso em vista, é possível dizer que, no tweet em discussão, há um investimento intensivo no controle das possibilidades interpretativas dos eventos ditatoriais brasileiros (disputa metapragmática), movido pelo negacionismo histórico, que preenche significantes flutuantes segundo conteúdos favoráveis às ideologias dos militares, de 1964, e do atual populismo bolsonarista. Tais elementos se encontram numa relação de aproximação espaço-temporal semioticamente produzida, ou seja, "o tempo, o espaço e os padrões de ação coincidem, criam significado e valor e podem ser comparados com outros cronotopos" (BLOMMAERT, 2015, p. 110).

Desse modo, muitas equivalências são projetadas entre o tempo-espaço dos excertos entextualizados no Twitter e o tempo-espaço atual. Algumas dessas equivalências podem oferecer recursos importantes para a compreensão dos embates semiótico-discursivos desencadeados nas interações discutidas adiante. Mediante enquadres autoritários são ordenados modos de interpretação que projetam sentidos segundos os quais: "violência de estado, tortura, desaparecimento forçado e assassinatos são preservação das instituições democráticas"; "oposição intelectual e política ao regime ditatorial são radicalização ideológica"; "paralisação de trabalhadores diante da injustiça nas relações de trabalho, mediante organizações sindicais, são graves, e estas, por sua vez, constituem-se numa ameaça à preservação das instituições democráticas"; "direito à manifestação pública, passeatas, protestos, atos e agremiações estudantis, artísticas, feministas, negras, indígenas, LGBT e de outros grupos minoritarizados são desordem social"; "potenciais mudanças de valores e costumes tradicionais rumo a 
modos de vida menos cis-heteronormativos ou desatrelados de uma moral cristãburguesa compulsória são corrupção generalizada".

No comentário que Bolsonaro faz ao seu próprio tweet, ainda na Figura 1, como já dito, outro trecho do texto é descontextualizado do mesmo editorial de 1984 e recontextualizado, estabelecendo todo um alinhamento a um modo de vida autoritário. A trajetória textual desse segundo fragmento semiótico aciona um terreno indexical de camadas ainda mais complexas e de nexos translocais que fazem sobrepor espacialidades e temporalidades ainda mais fluidas, atualizando, também, uma polifonia de vozes em movimento. Na referida entextualização, a postagem de Bolsonaro recupera uma fala do ex-presidente militar Costa e Silva, deflagrador do período mais violento da Ditadura, inaugurado com a edição do Ato Institucional n 5 (AI-5) ${ }^{12}$, conhecido como anos de chumbo (1968-1974), o qual, por sua vez, noutro cronotopo, aquele relativo à publicação do editorial de 1984, já havia sido entextualizado no discurso golpista de O Globo.

Temos, assim, a sobreposição indexical de sentidos autoritários que se atualizam à medida em que são recontextualizados na referida postagem, apontando para sua trajetória translocal e para as consequências da precipitação de sentidos emergentes. Esses, por sua vez, produzidos pela projetação discursos em circulação no tempo-espaço de um Brasil mergulhado na exceção democrática escancarada ou, ainda, pelos regimes semióticos instaurados pelas vozes múltiplas de líderes militares e de articuladores civis, a exemplo da imprensa, responsáveis por esse momento histórico violento.

Tais processos semióticos em curso na página oficial de um presidente da república democraticamente eleito, indicam a projeção de um tipo de enquadre metapragmático sustentado pelo alastramento da lógica negacionista, própria do bolsonarismo e de sua esfera digital de comunicação alternativa, a "Bolsosfera" (CESARINO, 2018). Como consequência dessa sobreposição entre os difusos limites de uma esfera privada, a Bolsosfera, e de uma esfera pública, a comunicação oficial da Presidência, avança o aprofundamento de uma retórica antidireitos humanos no discurso oficial do Estado brasileiro. Essa, por sua vez, consiste em

12.O AI-5, considerado "um golpe dentro de um golpe", significou uma maior intensificação do estado de exceção instaurado desde 1964, autorizando ao presidente militar, dentre outras coisas, fechar o Congresso Nacional, as Assembleias Legislativas e as Câmaras Municipais; suspender direitos políticos, caçar mandados eletivos; suspender a garantia de Habeas Corpus nos casos entendidos como crimes políticos contra a segurança nacional, a ordem econômica social e a economia popular; excluir qualquer uma das ações praticadas pelos agentes do Estado, incluindo suas polícias, em observância do AI-5, de qualquer tipo de apreciação judicial (Cf. BRASIL, 1968). 
uma parte fundamental para a consolidação do modelo autoritarista de governo e de comunicação governamental, próprio dos populismos de extrema-direita.

Em face da "moldura" produzida pelas trajetórias textuais que comparecem nos tweets presidenciais, há a possibilidade de que outros sujeitos se engajem com a prática discursiva inicial, seja para confirma-la e a seu conteúdo acerca da Ditadura, seja para disputar a filiação desses significantes flutuantes, num embate semióticodiscursivo que promove ainda mais mobilidade de recursos indexicais, conforme mostram as respostas ${ }^{13}$ apresentados Figura 2, a seguir. Esse processo torna saliente o fato de que, no discurso político, o estatuto de verdade histórica atribuído a fatos específicos está em permanente disputa, especialmente em tempos de pós-verdade, fake-news e de digitalização do político (CESARINO, 2020; NEMER, 2019).

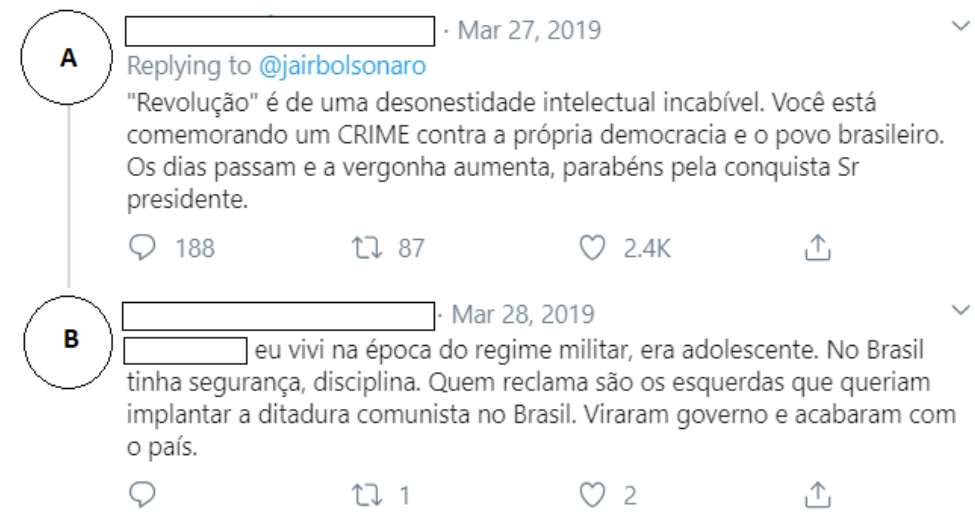

Figura 2: Embate entre bolsonaristas e seus opositores políticos no Twitter. Fonte: <https://twitter.com/jairbolsonaro/status/1111005083196706817A. Acesso em: 19 fev. 2020.

Na Figura 2, enquanto o investimento discursivo do comentador Aéresponsivo à postagem do próprio Bolsonaro, no sentido de deslegitimar a hegemonia dos signos performada pelas ideologias que regulam a instância metapragmática então

13. Os tweets em resposta à postagem inicial de Jair Bolsonaro, que compõem o material de análise deste artigo, foram selecionados do conjunto de 1.900, ordenadas pela plataforma em sequência cronológica, em função da ordem de aparecimento e da intensidade da fricção semiótico-discursiva produzida pelos enquadres metapragmáticos projetados por tais respostas, em relação aquele instaurado pelo tweet inicial, conforme discutido na seção 3 deste artigo. Naquelas postagens disparadas por perfis pessoais, usando recursos do Word for Windows 10, realizamos procedimentos a fim de torná-las anônimas, já naquelas feitas por perfis políticos, as identificações foram mantidas. Todas as publicações aqui produzidas são de domínio público, segundo configurações de privacidade do próprio Twitter. 
projetada, o comentador B volta-se para o comentador A, realizando uma projeção de signos que altera o padrão indexical por ele mobilizado, reestabelecendo, assim, a hegemonia encenada pelos sentidos do discurso bolsonarista. Essa dinâmica de fricção de sentidos indexicalizados e, consequentemente, de projeções identitárias, pode ser inferida pelas tentativas feitas por ambos os comentadores no sentido de, entre si e em relação ao tweet da Figura 1, moverem os terrenos indexicais arregimentados pelos textos em trânsito. Assim, instauram a fricção entre os regimes de autorização interpretativa vigentes nos enquadres metapragmáticos semioticamente disputados.

Nesse processo, é interessante perceber como o comentador A descontextualiza um fragmento da postagem de Bolsonaro - "Revolução" - e o recontextualiza em seu próprio texto, ou seja, entextualizando-o, mas isso de forma paródica, uma vez que, ao fazer o texto dobrar-se reflexivamente sobre si mesmo, predica tal fragmento, ou melhor, o conjunto de valores e ideologias que ele indexicaliza diante do enquadre metapragmático bolsonarista, como desonestidade intelectual incabivel e ainda como um CRIME contra a democracia e o povo brasileiro. Vale registrar que a referida disputa se concentra também em torno do significante vazio povo brasileiro. Se no tweet presidencial - após os efeitos das entextualizações sucessivas no discurso ditatorial de Costa e Silva e no golpista de Roberto Marinho - tal significante é definido segundo perspectivas autoritárias que restringem sua significação ao grupo de civis que apoiaram o Golpe de 1964 e a Ditadura, no discurso do comentador A, por sua vez, tal significante é tomado para instaurar sentidos democráticos, visto que significa como povo brasileiro aqueles para quem seria um CRIME interpretar os eventos ditatoriais como "Revolução".

Nessa disputa pautada na movimentação dos terrenos indexicais produzidos pelas trajetórias de textos mobilizadas nas interações sob análise, o comentador B volta a operar uma calibragem reflexiva da metapragmática que orienta a interpretação dos referidos signos em trânsito/em fricção semiótica. Para tanto, predica os eventos em disputa interpretativa como regime militar, afastando-se tanto da predicação Revolução de 1964 mobilizada por Bolsonaro, quanto da predicação CRIME acionada pelo comentador A. Além disso, recorrendo a um discurso experiencial, avalia esse momento nacional como sendo marcado por segurança e disciplina, signos cuja arregimentação pode ser identificada em alinhamento com o ordenamento indexical da predicação povo brasileiro, conforme o enquadre do discurso bolsonarista. Esse último é posicionado em fricção com os discursos autoritários para os quais apontam os signos indexicais os esquerdas e ditadura comunista no Brasil, conforme discutirei a seguir. 
Em disputa direta com o enquadramento forjado na postagem do comentador B, da Figura 2, o qual indexicaliza sentidos do revisionismo histórico da extremadireita, o tweet reproduzido na Figura 3, na sequência, entextualiza discursos que se movimentam produzindo uma trajetória textual que remonta à Marcha das Familias com Deus pela Liberdade, ocorrida em São Paulo, em 19 de março de 1964. Esse evento marca, emblematicamente, o apoio civil à Ditadura.

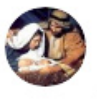

Anti Socialismo/Comunismo@eantiesquerdaBRA.Mar 27, 2019

Replying to @jairbolsonaro

Orgulho por ter um presidente Militar, graças a vcs nós não estamos em situação ainda pior.

이 Viva 1964!!!!

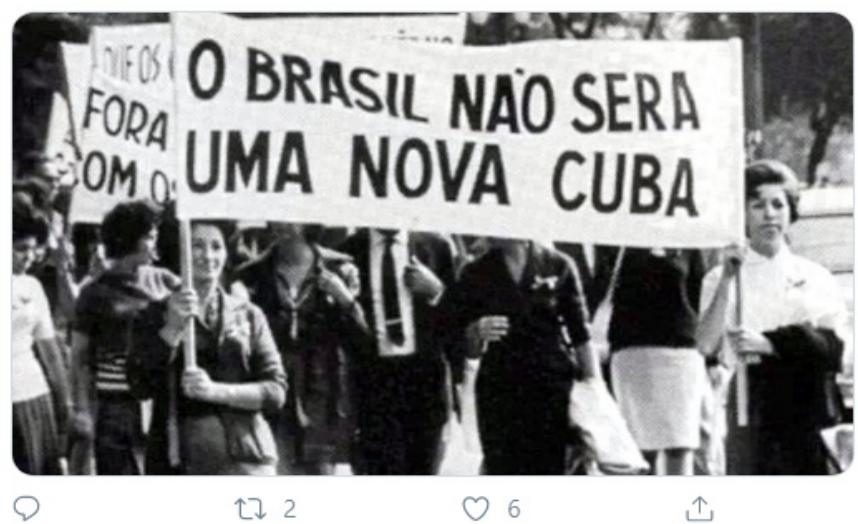

Figura 3: Tweet que reproduz fotografia da Marcha das Famílias com Deus pela Liberdade. Fonte: <https://twitter.com/jairbolsonaro/status/1111005083196706817>. Acesso em: 19 fev. 2020.

O processo de entextualização produzido por esse tweet do que parece ser uma página de ativismo político bolsonarista online, nomeada como Anti Socialismo/ Comunismo(@antiesquerdaBRA), aciona signos multissemióticos que mobilizam complexas camadas indexicais. Elementos de diferentes naturezas semióticas (as inscrições verbais, a imagem religiosa da Sagrada Família na identificação do perfil, os emojis de bandeiras do Brasil, os efeitos de enquadramento da fotografia) estão amalgamados, produzindo uma trajetória na qual diferentes textos "dialogam entre si, mobilizam novos sentidos e precipitam significados outros" (MELO, 2019, p. 234), indexicalizando sentidos de ordem religiosa, militarista, patriótica e anticomunista que reforçam o enquadre do discurso bolsonarista online.

A referidas trajetórias textuais precipitam sentidos translocais, especialmente se pensarmos que o cronotopo projetado por essa entextualização remonta a uma 
resposta conservadora e elitista da sociedade brasileira, frente às Reformas de Base anunciadas por João Goulart em comício realizado na Central do Brasil, no Rio de Janeiro, em 13 de março de 1964. Tais mudanças diziam respeito a uma série de reformas administrativas, jurídicas e econômicas que feriam os interesses das classes média e alta, já que tinham como objetivo diminuir a desigualdade do país e promover, dentre outras coisas, a Reforma Agrária e a taxação sobre grandes fortunas, pautas até hoje controversas na política nacional. Esse evento foi identificado como uma ameaça comunista ou ameaça vermelha por setores militares, industriais, religiosos e outros conservadores da sociedade brasileira (GORENDER, 2014).

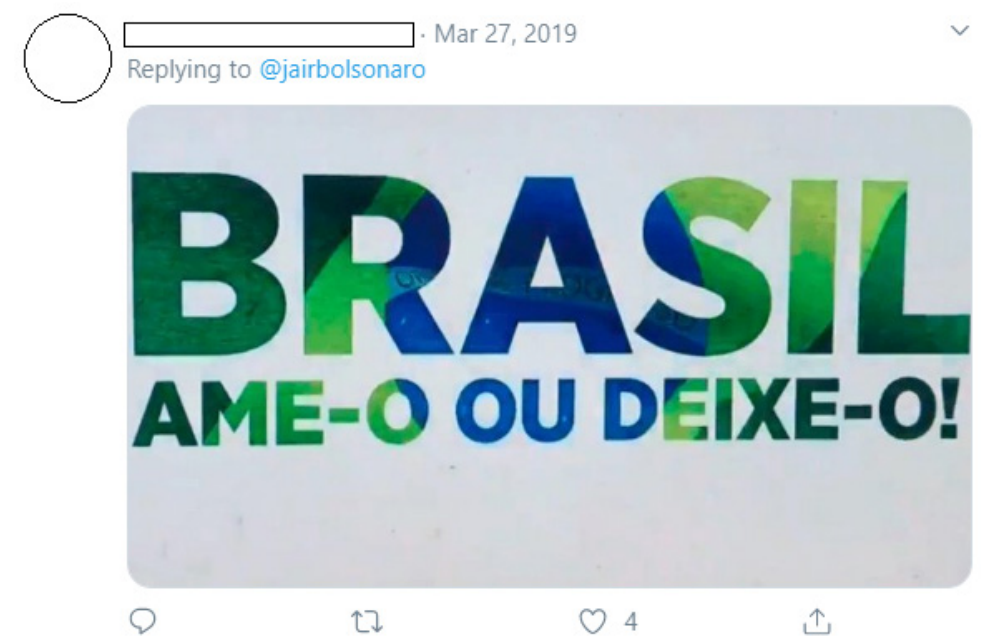

Figura 4: Tweet que reproduz slogan da propaganda oficial do Regime Civil-Militar. Fonte: <https://twitter.com/jairbolsonaro/status/1111005083196706817>. Acesso em: 19 fev. 2020.

$\mathrm{Na}$ figura 4, que registra um tweet em resposta à postagem inicial do perfil @jairbolsonaro, é possível inferir uma relação dialética de vozes e significados socioculturais para os quais apontam os signos acionados. $O$ enquadre metapragmático validado pelo comentador recontextualiza um dos slogans da propaganda oficial da Ditadura Civil-Militar brasileira, promovida pela Assessoria Especial de Relações Públicas (AREP) do Regime, criada em 1970, pelo Governo Médici. O texto Brasil, ame-o ou deixe-o!, que deveria, segundo a ideologia antidemocrática do Regime, inspirar valores da soberania nacional aos brasileiros, era, na verdade, uma nítida cópia do slogan USA, love or leave it!, um tipo de chamamento do governo dos EUA a uma postura patriótica dos estadunidenses que deveria se traduzir no apoio 
irrestrito ao terror da Guerra do Vietnã, fazendo, assim, frente aos movimentos pacifistas e pró-direitos humanos que queriam o fim da guerra.

Sustentando uma perspectiva sobre a produção dos significados que leve em conta o fato de que as viagens e a mobilidade afetam práticas textuais e interpretativas (FABRÍCIO, 2013), as trajetórias para onde apontam os sentidos indexicais acionados no processo de entextualização registrado na Figura 4 atualizam no cronotopo projetado na interação em análise, e no discurso presidencial brasileiro, o projeto de uma visão ufanista de Brasil, segundo a qual construir um país grande e forte era uma missão civilizadora que cabia aos militares (RAMOS, 2015). Para além disso, o tom imperativo da mensagem atualiza o sentido autoritário que impunha a todos aqueles que desejavam ser intitulados como brasileiros uma identificação plena com projeto de nação grande, forte, ordeira, pacífica, conforme a ideologia do Regime. Aos que se submetiam a essa rede de significados cabia-lhes amar o Brasil, enquanto aos outros, que não estariam abarcados pelo conteúdo autoritário do significante vazio povo brasileiro, como já vimos em outros momentos dessa trajetória textual, cooptado pelo discurso ditatorial, os críticos ao regime, por exemplo, restava-lhes deixar o Brasil, quer pela destituição de seus direitos políticos, quer pelo exílio, pelo desaparecimento forçado, pela tortura ou pelo extermínio político.

\section{CONSIDERAÇÕES FINAIS}

Certamente, uma breve sumarização das questões epistemológicas centrais perseguidas nas trajetórias deste artigo, entre esforços teóricos, metodológicos e analíticos, apontaria, dentre outros pontos difusos: a) a sistemática instrumentalização das flutuações de significantes vazios, próprios da mecânica política populista, com vistas à implementação de revisionismos ideológicos e negacionismos bistóricos estratégicos para a manutenção de certo efeito de hegemonia dos sentidos políticos do bolsonarismo online sobre a Ditadura Civil-Militar; $b$ ) a insistente indexicalização de sentidos de base autoritária, antidemocrática e repulsiva aos direitos humanos que são (re) instaurados nas trajetórias textuais mobilizadas no discurso das redes digitais bolsonaristas, a exemplo do locus desta pesquisa; c) a intensa fricção semiótico-discursiva produzida em processos de disputa por enquadres metapragmáticos entre articuladores digitais do bolsonarismo e seus oponentes em espaços públicos virtuais.

Desse modo, a análise das práticas discursivas sobre as quais procurei produzir interpretações neste trabalho, especialmente em tempos de populismos emergindo dos espectros mais radicais da extrema-direita e da contínua digitalização do político, enseja reinvenções metodológicas e teórico-analíticas mais estruturais 
nos estudos da linguagem. Tais propostas devem levar em conta, principalmente, a aceleração de fluxos e trânsitos cronotrópicos de signos; o caráter fluido e móvel dos regimes de durabalibidade semiótica de um tempo histórico específico; bem como os processos de agência não-humana na produção de processos de significação indexicais do político, esses últimos apenas sinalizados aqui. Nesse sentido, a busca pelo entendimento dos modos como dinâmicas (meta)pragmáticas e trajetórias de signos funcionam em práticas locais da comunicação política contemporânea, especialmente daquelas digitalmente mediadas, oferecem possibilidades de compreensão de fenômenos sociopolíticos mais amplos.

\section{REFERÊNCIAS}

BLOMMAERT, Jan. (2015). Chronotopes, Scales, and Complexity in the Study of Language in Society. Annu. Rev. Antbropol., n. 44, p. 105-116.

BLOMMAERT, Jan. (2019). Political discourse in post-digital societies. Em aberto. Tilburg, p. 1-10. Disponível em: <https://www.tilburguniversity.edu/research/institutes-andresearch-groups/babylon/tpcs >. Acesso em: 19 fev. 2020.

BOAVENTURA, Júlio Cesar S. (2018). Suburbanos e farofeiros em trânsito: entre a fricção e a (re) construção textual de subjetividades fora do lugar. Tese (Doutorado em Linguística Aplicada), UFRJ, Rio de Janeiro.

BOLSONARO, Jair. (2018). Entrevista do candidato Jair Bolsonaro Programa Roda-Viva da TV Cultura. Youtube. 30 de julho de 2018. Disponível em: <https://www.youtube.com/ watch?v $=1$ DL59dkeTi0 > Acesso em: 10 jan. 2020.

BRASIL (1968). Ato Institucional no 5, de 13 de dezembro de 1968. Disponível em: <http://www. planalto.gov.br/ccivil_03/ait/ait-05-68.htm>. Acesso em: 10 jan. 2020.

BRASIL. (2014). Relatório final da Comissão Nacional da Verdade. Em aberto. Brasília.

CÂMARA DOS DEPUTADOS (2005). Notas taquigráficas do discurso do deputado Jair Bolsonaro por ocasião do transcurso do Dia do Exército Brasileiro. Documento aberto. Brasília: Governo Federal

CESARINO, Letícia. (2018). Como vencer uma eleição sem sair de casa: um estudo de caso sobre o populismo digital de Jair Bolsonaro. 72 slides. Disponível em: < https://www. academia.edu/37654690/Como_vencer_uma_elei\%C3\%A7\%C3\%A3o_sem_sair_ 
de_casa_um_estudo_de_caso_sobre_o_populismo_digital_na_campanha_de_Jair Bolsonaro_ppt_>. Acesso em: 25 mar. 2020.

CESARINO, Letícia. (2019). Identidade e representação no bolsonarismo: corpo digital do rei, bivalência conservadorismo-neoliberalismo e pessoa fractal. Revista de Antropologia, v. 62 n. 3 , p. 530-557.

CESARINO, Letícia. (2020). Como vencer uma eleição sem sair de casa: ascensão do populismo digital no Brasil. Internet \& Sociedade, n. 1, v. 1, fev., p. 91-120.

FABRÍCIO, Branca F. (2013). A "outridade lusófona" em tempos de globalização: identidade cultural como potencial semiótico. In: Luiz Paulo da Moita Lopes. (Org.) Português no século XXI: ideologias linguísticas. São Paulo: Parábola, 2013, p. 144-168.

FABRÍCIO, Branca F. (2014). Transcontextos educacionais: gêneros e sexualidades em trajetórias de socialização na escola. In: SILVA, D. et al. (Orgs.). Nova Pragmática: modos de fazer. São Paulo: Cortez Editora. p. 145-189.

GAlvÃO, Ana Carolina; ZAIDAN, Junia C. S. M.; SALGUEIRO, Wilberth. (2019). Foi golpe! O Brasil de 2016 em análise. Campinas: Pontes Editores, 2019.

GORENDER, Jacob. (2014). A sociedade cindida. Revista de Estudos Avançados, São Paulo, v. 28, n. 80 .

KIELING, Camila. (2016). Autoritarismo no discurso da imprensa brasileira durante o golpe de 1964. Revista Extraprensa, São Paulo, v. 1, n. 10, p. 3-17.

LACLAU, Ernesto. (2005) A razão polulista. São Paulo: Três Estrelas/Buenos Aires: Ariel.

LACLAU, Ernesto. (2014). The rethorical fundation of Society. London: Verso.

LATOUR, Bruno. (2012). Reagregando o social: uma introdução à teoria do ator-rede. Salvador: EDUFBA-EDUSC.

MELO, Glenda. (2019). Anúncios de comercialização de escravos nos séculos XIX e XXI: trajetória textual, entextualizações e ordens indexicais. In: SZUNDY, P. T. C.; TILIO, R.; MELO, G. C. V . (Orgs.). Inovações e desafios epistemológicos em Linguística Aplicada: perspectivas sul-americanas. São Paulo: Pontes, 229-260.

MOITA LOPES, Luís Paulo; FABRÍCIO, Branca F. (2019). Por uma 'proximidade crítica' nos estudos em Linguística Aplicada. Calidoscópio, v. 14, n. 4, p. 711-423. 
NAPOLITANO, Marcos. (2015). Negacionismos e Revisionismos: o conhecimento histórico sob ameaça. Em aberto. São Paulo, p. 1-4. Disponível em: <http://historia.fflch. usp.br/sites/historia.fflch.usp.br/files/u206/Texto\%20S\%C3\%ADntese\%20\%20 Negacionismo\%20\%282\%29.pdf>. Acesso em: 19 fev. 2020.

NAPOLITANO, Marcos. (2019). Golpe de Estado: entre o nome e a coisa. Estudos Avançados, São Paulo, v. 96, n. 33, p. 397-420.

NEMER, David. (2019). A radicalização invisivel da direita brasileira no WhatsApp., Disponível em: <https://www. huffpostbrasil.com/entry/whatsapp-bolsonaro_ br_5d5b5487e4b0d1e11366e0a9>. Acesso em: 10 mar. 2020.

PASQUINI, Patrícia. (2018). 90\% dos eleitores de Bolsonaro acreditaram em fake news, diz estudo. Disponível em: < https://www1.folha. uol.com.br/poder/2018/11/90-dos-eleitoresdebolsonaro-acreditaram-em-fake-news-diz-estudo >. Acesso em: 10 mar. 2020.

PINTO, Joana P. (2019). É só mimimi? Disputas metapragmáticas em espaços públicos online. Interdisciplinar, São Cristóvão, v. 31, jan./jun., p. 221-236.

QUIJANO, Aníbal. (2005). Colonialidade do poder, eurocentrismo e América Latina. In: CONSEJO LATINOAMERICANO DE CIENCIAS SOCIALES. A colonialidade do saber: eurocentrismo e ciências sociais. Perspectivas latino-americanas. Buenos Aires: CLACSO, 2005. p. 117-142.

RAMOS, Diego. (2015). Propaganda e ufanismo na ditadura militar brasileira: a apropriação do discurso ufanista pelo sindicalismo docente de Niterói. Revista Contemporânea, ano 5, v. 2, n. 8 .

SCHWARCZ, Lilia. (2019). Sobre o autoritarismo brasileiro. São Paulo: Companhia das Letras.

SILVA, Daniel. (2014). O texto entre a entextualização e a etnografia: um programa jornalístico sobre belezas subalternas e suas múltiplas recontextualizações. Linguagem em (Dis)curso - LemD, Tubarão, v. 14, n. 1, pp. 67-84.

SILVA, Daniel. (2019). Enregistering the nation: Bolsonaro's populist branding of Brazil. To appear in: I. Theodoropoulou \& J. Woydack (eds). Language and Country Branding. London: Routledge.

SILVA, Danillo C. P. (2019). (Meta)pragmática da violência linguística: patologização de vidas trans em comentários online. Trabalbos em Linguística Aplicada, Campinas, v. 58, n. 2, maio/ago., p. 956-985. 
SILVERSTEIN, Michel. (1993). Metapragmatic discourse and metapragmatic function. In: LUCY, J. (Org.) Reflexive language: Reported speech and metapragmatics. Cambridge: Cambridge University Press, p. 33-58.

SZUNDY, Paula; FABRÍCIO, Branca F. (2019). Linguística Aplicada e indisciplinaridade no Brasil: promovendo diálogos, dissipando brumas e projetando desafios epistemológicos. In: SZUNDY, P. T. C.; TILIO, R.; MELO, G. C. V . (Orgs.). Inovações e desafios epistemológicos em Linguística Aplicada: perspectivas sul-americanas. São Paulo: Pontes, 229-260.

VARIS, Piia.; BLOMMAERT, Jan. (2015). Conviviality and collectives on social media: virality, memes, and new social structures. Multilingual Margins, v. 2, n. 1, p. 31-45.

Recebido: 21/2/2020

Aceito: 21/3/2020

Publicado: 26/6/2020 